\title{
A Descriptive Study of Clinicoradiological and Serum Biomarker Profile in Patients Who Died due to COVID-19 Infection in a Tertiary Care Hospital
}

\author{
Saikat Banerjee ${ }^{1}$, Amitava Pal ${ }^{2}$, Priyanka Ghosh ${ }^{3}$, Subhasis Mukherjee ${ }^{4}$, Supriya Sarkar ${ }^{5}$
}

\begin{abstract}
Background:The coronavirus infectious disease-2019 (COVID-19) infectivity and death rates are steadily falling as we reach the declining phase of the second wave. However, there is still no surety as to when we will be finally free from the pandemic and mortality will always remain the most important factor of concern.

Materials and methods: One hundred patients who died due to COVID-19 were sampled using systematic random sampling from our hospital, and demographic, clinical, blood, and radiological investigations data were collected retrospectively. An analysis of these parameters was then done using descriptive statistical methods to point out potential risk factors for mortality, which may help in formulating future hypotheses.

Results: The mean age was 68.3 years, and $69 \%$ were more than 65 years of age. Sixty-one percent were males, suggesting a male preponderance. Diabetes and hypertension were the most common comorbidities. Oxygen saturation $<90 \%$, respiratory rate $>24 /$ minute, heart rate $>90 /$ minute, impaired level of consciousness, National Early Warning Score (NEWS) $>12$ seem to be important mortality predictors. Neutrophil/lymphocyte ratio of more than 5.2, lymphopenia, low platelet counts, low serum albumin, electrolyte disturbances, high creatinine levels, and high serum inflammatory biomarker levels all appear to contribute to mortality in COVID-19 patients.

Conclusions: More studies need to be performed to test for the variety of hypotheses proposed in this study. Early identification of these mortality indicators may help us reduce mortality in such cases by timely and appropriate intervention.

Keywords: COVID-19, Mortality, National Early Warning Score, Serum inflammatory markers.

Bengal Physician Journal (2021): 10.5005/jp-journals-10070-7052
\end{abstract}

\section{INTRODUCTION}

Coronavirus infectious disease-2019 (COVID-19) is one of the leading topics of discussion in the medical world and beyond today. As the pandemic still rages on after the first and second waves, we still speculate about the possibility of a third wave and we are all trying to learn about the disease and find ways to fight it, in the best way that we can.

By the end of June 2021, around 40 lakh deaths have been reported worldwide related to COVID-19, and out of them, around 4 lakh deaths are from India, a sizable $10 \%$ of the worldwide death count. ${ }^{1}$

Needless to say, it is imperative that we try to learn from whatever experience we have gathered over the last 18 months or so, regarding the pathophysiology of the disease and how it can lead to the death of the patient. It is important to point out the predictors of mortality in COVID-19-positive patients so that we can be more vigilant toward patients carrying more risk of mortality.

To this end, from a statistical viewpoint, we need to formulate appropriate hypotheses as to what may be the predictors of mortality for COVID-19. The first step to formulate meaningful hypotheses would be to conduct a descriptive analysis of the deaths due to COVID-19 and try to understand the possible candidates for the factors that might lead to increased mortality risks of these patients.

The following study has been done on patients who died due to COVID-19 and a descriptive analysis has been performed on their
${ }^{1-5}$ Department of Respiratory Medicine, College of Medicine and Sagore Dutta Hospital, Kolkata, West Bengal, India

Corresponding Author: Subhasis Mukherjee, Associate Professor, Department of Respiratory Medicine, College of Medicine and Sagore Dutta Hospital, Kolkata, West Bengal, India, Phone: +91 9830145290, e-mail: drsubhasismukherjee@yahoo.in

How to cite this article: Banerjee S, Pal A, Ghosh P, et al. A Descriptive Study of Clinicoradiological and Serum Biomarker Profile in Patients Who Died due to COVID-19 Infection in a Tertiary Care Hospital. Bengal Physician Journal 2021;8(2):38-44.

Source of support: Nil

Conflict of interest: None

history, clinicoradiological profile, and investigational profile to try and search for some important insights into the factors that predict increased mortality risk in such patients.

\section{Aims and Objectives}

- To describe the basic demographical and clinical profile of patients who died due to COVID-19.

- To describe the routine investigations, liver, renal, and inflammatory biomarkers profiles in patients who died due to COVID-19.

- To describe the radiological profile in patients who died due to COVID-19. 


\section{Materials and Methods}

The study design is a retrospective, observational, and descriptive single-center study. The study population for this study was all the COVID-19-related deaths that occurred from September 2020 to April 2021 in the College of Medicine and Sagore Dutta Hospital, which was a COVID-19-dedicated hospital for most of the period under study.

According to our database, there were a total of 669 deaths out of a total of over 4,500 COVID-19-positive patients admitted to the wards, high dependency units, and intensive care units of the hospital.

Out of these, relevant data were available for 503 of these 669 patients. Next, systematic random sampling was performed and every fifth patient was chosen for our study to get a sample population of size 100 for analysis.

After getting prior approval from the Institutional Ethics Committee, data were collected regarding patient particulars, previous hospitalization, contact history, drug history, and comorbidities. Clinical parameters, National Early Warning Scores (NEWS), and routine blood investigations data along with radiological findings and inflammatory markers were analyzed. The duration of symptoms and length of hospital stay were also considered for the analysis.

\section{Statistics}

All continuous variables were described using mean and standard deviation (SD) and categorical variables using percentages and proportions. Some continuous variables were converted to categorical variables to provide a better understanding and meaningful insights toward the formulation of future hypotheses regarding mortality indicators for COVID-19.

\section{Results and Analysis}

Out of the 100 patients taken up for the study, 61\% were males and $39 \%$ were females. The mean age was 68.3 years with a SD of 13.9 years. Sixty-nine percent of the study population were over 65 years of age (Figs 1 and 2).

The mean duration of illness was 14.6 days with a SD of 10.8 days. Seventy-four percent of the patients had one or two comorbidities and $19 \%$ of them had no reported comorbidity. Only $7 \%$ of patients had more than two comorbidities. Diabetes mellitus and systemic hypertension were found in $57 \%$ and $58 \%$ of patients, respectively. Cerebrovascular accident (CVA) (5\%), hypothyroidism (4\%), and chronic kidney disease (CKD) (3\%) were other notable comorbidities (Table 1).

History of hospitalization in last 6 months was present in 15\% of patients, travel history in last 14 days in $19 \%$ of patients, contact history with COVID-19-positive patient in 17\% of patients, and only $7 \%$ of patients were on any immunosuppressive drugs (Table 1). None of the patients were pregnant or suffered an intrauterine fetal demise.

\section{Clinical Profile}

The mean oxygen saturation for the patients was $86.5 \%$ with a SD of $11.5 \%$ with $30 \%$ of patients having oxygen saturation of less than $80 \%$ and $57 \%$ having oxygen saturation of less than $90 \%$ even with supplemental oxygen support (Table 2).

The mean respiratory rate of patients was around 25/minute with a SD of around 7 breaths/minute. Nineteen percent of the

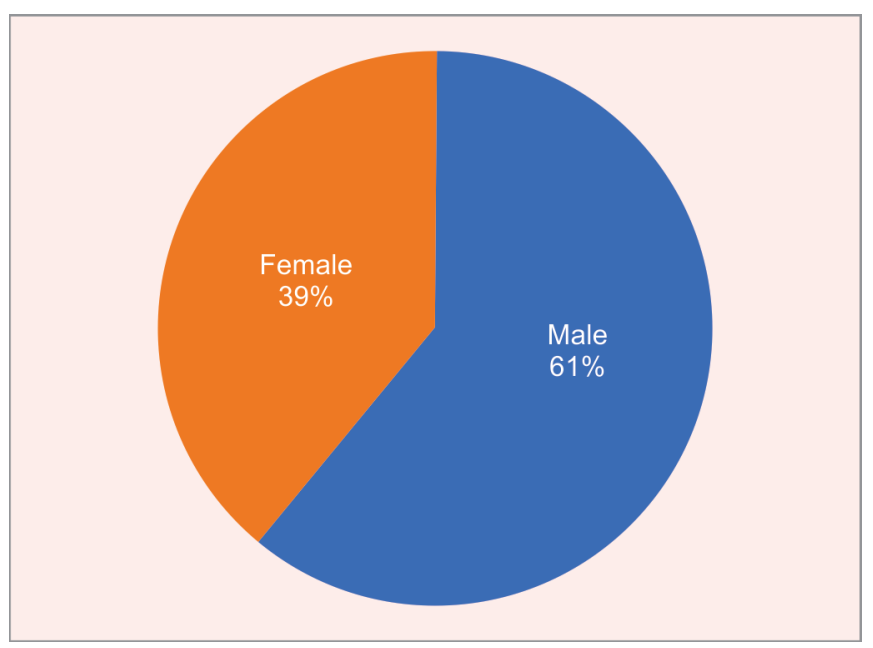

Fig. 1: Gender distribution of COVID-19 related deaths $(n=100)$

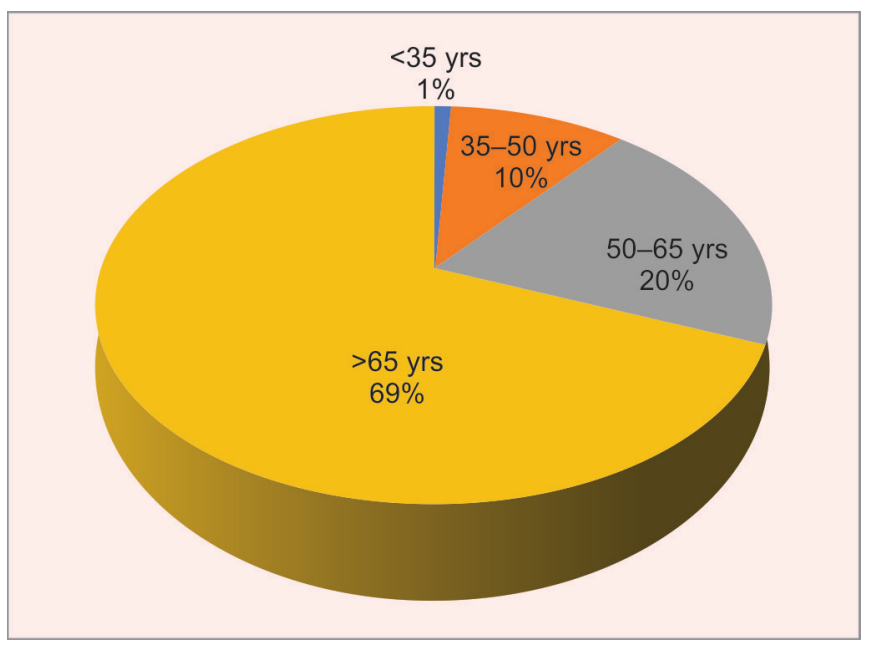

Fig. 2: Age distribution of COVID-19-related death $(n=100)$

patients had a respiratory rate of over $30 /$ minute and $43 \%$ had rates of over $24 /$ minute.

The mean heart rate was $98 /$ minute with a SD of $27 /$ minute. Twenty percent of patients had a heart rate over $120 /$ minute and $61 \%$ had rates of over $90 /$ minute. Only $12 \%$ of patients had bradycardia.

The mean systolic blood pressure (SBP) was around $115 \mathrm{~mm} \mathrm{Hg}$ with a SD of $28 \mathrm{~mm} \mathrm{Hg}$. A sizeable $23 \%$ of patients had SBP of less than $90 \mathrm{~mm} \mathrm{Hg}$ while only 3\% had SBP of over $160 \mathrm{~mm} \mathrm{Hg}$.

The mean NEWS for COVID-19 patients was around 17 with a SD of around 6 . The majority of patients (76\%) had an NEWS of more than 12 (Table 2).

On chest auscultation, $60 \%$ of the patients had bilateral crepitations and $27 \%$ had reduced vesicular breath sounds, while bronchial breath sounds were present in $5 \%$ of patients and in $8 \%$ of patients, chest auscultation was absolutely normal.

With regards to the level of consciousness, $9 \%$ of patients were unresponsive, $14 \%$ were responsive only to painful stimuli, and $51 \%$ were responsive to verbal stimuli too. 
Table 1: Demographic and clinical characteristics of patients $(n=100)$

\begin{tabular}{lc}
\hline Gender (M = Male, F = Female) & M: $61 ; \mathrm{F}: 39$ \\
Mean age in years (SD) & $63.8(13.93)$ \\
Duration of Illness in days (SD) & $14.6(10.77)$ \\
Comorbidities & \\
- Systemic hypertension & $58(58 \%)$ \\
- Diabetes mellitus & $57(57 \%)$ \\
- Cerebrovascular accident & $5(5 \%)$ \\
- Hypothyroidism & $4(4 \%)$ \\
- Chronic kidney disease & $3(3 \%)$ \\
- Acute kidney injury & $2(2 \%)$ \\
- Ischemic heart disease & $2(2 \%)$ \\
- Chronic obstructive pulmonary disease & $1(1 \%)$ \\
- Asthma & $1(1 \%)$ \\
- Retinopathy & $1(1 \%)$ \\
- Neuropathy & $1(1 \%)$ \\
- Dyslipidemia & $1(1 \%)$ \\
- Seizure disorder & $1(1 \%)$ \\
- Renal stones & $1(1 \%)$ \\
- Brain tumor & $1(1 \%)$ \\
- Metastatic breast cancer & $1(1 \%)$ \\
- Guillian-Barre Syndrome & $1(1 \%)$ \\
- Liver cholangiocarcinoma & $1(1 \%)$ \\
No comorbidities & $1(1 \%)$ \\
1-2 comorbidities & \\
>2 comorbidities & $19(19 \%)$ \\
History of hospitalization in last 6 months & $74(74 \%)$ \\
Immel history in last 14 days present & $15(15 \%)$ \\
\hline
\end{tabular}

\section{Routine Investigations}

The mean hemoglobin for the patients was $11.5 \mathrm{~g} / \mathrm{dL}$ (SD 2.55), mean total leukocyte count was 11,809 (SD 6470), mean neutrophil and lymphocyte percentages were $86.63 \%$ (SD 13.36\%) and $10.03 \%$ (SD $11.79 \%)$, respectively, and mean platelet count was $183,685 / \mathrm{mm}^{3}$ (SD 91726). The mean neutrophil-to-lymphocyte ratio ( $\mathrm{N} / \mathrm{L}$ ratio) was 23.62 (SD 36.15) (Table 2).

Nine percent of patients had severe anemia; moderate anemia was present in $17 \%$ of patients; and mild anemia was present in $26 \%$ of patients. Total leukocyte count was more than $11,000 / \mathrm{mm}^{3}$ in $52 \%$ of patients and less than $4,000 / \mathrm{mm}^{3}$ in $7 \%$ of patients (Fig. 3 ).

The N/L ratio was more than 3.13 in a staggering $94 \%$ of patients, with values over 5.2 in $87 \%$ of patients and over 10.0 in $58 \%$ of patients. The platelet count was less than $1,50,000 / \mathrm{mm}^{3}$ in $47 \%$ of patients and was normal in $52 \%$ of patients (Fig. 3).

\section{Liver Function Tests}

Out of the liver function parameters, mean serum total protein was $6.3 \mathrm{~g} / \mathrm{dL}$ (SD 1.5), mean serum albumin was $3.01 \mathrm{~g} / \mathrm{dL}$ (SD 0.75 ) with mean total and direct bilirubin 0.85 (SD 1.08) and 0.39 (SD 0.87 ) $\mathrm{mg} / \mathrm{dL}$, respectively. The mean serum glutamic pyruvic transaminase (SGPT) was $77 \mathrm{U} / \mathrm{L}$ (SD 60), mean serum glutamic oxaloacetic transaminase (SGOT) was $80 \mathrm{U} / \mathrm{L}$ (SD 44), and mean alkaline phosphatase (ALP) was $147 \mathrm{U} / \mathrm{L}$ (SD 215).

Forty-six percent had serum protein levels less than $6 \mathrm{~g} / \mathrm{dL}$ and $37 \%$ had normal serum protein levels. Seventy-nine percent of
Table 2: Clinical examination and routine investigation parameters $(n=100)$

\begin{tabular}{|c|c|}
\hline $\begin{array}{l}\text { Oxygen saturation with optimal } \\
\text { supplemental oxygen support [mean (SD)] }\end{array}$ & $86.51 \%(11.53)$ \\
\hline Respiratory rate [mean (SD) per minute] & $25.12(7.19)$ \\
\hline Systolic BP [mean (SD) mm Hg] & $114.78(27.69)$ \\
\hline Heart rate [mean (SD) per minute] & $97.75(27.17)$ \\
\hline Temperature [mean (SD) $\left.{ }^{\circ} \mathrm{C}\right]$ & $97.71(0.73)$ \\
\hline National Early Warning Score[mean (SD)] & $16.69(5.56)$ \\
\hline \multicolumn{2}{|l|}{ Level of consciousness } \\
\hline $\begin{array}{ll}\text { - } & \text { Alert } \\
\text { - } & \text { Responsive to verbal stimuli } \\
\text { - } & \text { Responsive to painful stimuli } \\
\text { - Unresponsive }\end{array}$ & $\begin{array}{c}26(26 \%) \\
51(51 \%) \\
14(14 \%) \\
9(9 \%)\end{array}$ \\
\hline Hemoglobin[mean (SD) mg/dL] & $11.52(2.55)$ \\
\hline Total WBC count [mean (SD)/mm³] & $11809.51(6469.72)$ \\
\hline \multicolumn{2}{|l|}{ Differential count [mean (SD)\%] } \\
\hline $\begin{array}{ll}\text { - } & \text { Neutrophils } \\
\text { - } & \text { Lymphocytes } \\
\text { - } & \text { Monocytes } \\
\text { - } & \text { Eosinophils } \\
\text { - } & \text { Basophils } \\
\text { - } & \text { N/L ratio [mean(SD)] }\end{array}$ & $\begin{array}{c}86.63 \%(13.36 \%) \\
10.03 \%(11.79 \%) \\
2.44 \%(2.02 \%) \\
0.28 \%(0.49 \%) \\
0.33 \%(0.59 \%) \\
23.63(36.16)\end{array}$ \\
\hline Platelets [mean (SD) per $\mathrm{mm}^{3}$ ] & $18365.09(91725.66)$ \\
\hline Urea [mean (SD) mg/dL] & $68.25(55.32)$ \\
\hline Creatinine [mean (SD) mg/dL] & $1.51(1.71)$ \\
\hline Sodium[mean (SD) mEq/dL] & $137.77(12.88)$ \\
\hline Potassium [mean (SD) mEq/dL] & $4.38(0.84)$ \\
\hline \multicolumn{2}{|l|}{ Liver function test [mean (SD)] } \\
\hline - Total protein (g/dL) & $6.29(1.52)$ \\
\hline - Serum albumin (g/dL) & $3.02(0.74)$ \\
\hline - Total bilirubin (g/dL) & $0.85(1.08)$ \\
\hline - Direct bilirubin (g/dL) & $0.39(0.87)$ \\
\hline - S SGPT (ALT) (IU/L) & $76.89(60.18)$ \\
\hline • $\quad$ SGOT (AST) (IU/L) & $79.65(44.17)$ \\
\hline - $\operatorname{ALP}(I U / L)$ & $146.85(215.36)$ \\
\hline
\end{tabular}

patients had hypoalbuminemia while $20 \%$ of patients had a normal albumin level (Fig. 3).

Eight percent of patients had a raised total bilirubin level, out of which most were due to increased direct bilirubin. Around $51 \%$ of patients had an increased SGPT and $73 \%$ of patients had increased SGOT, but ALP was increased in only $20 \%$ of patients. Even so, only 3 and $6 \%$ of patients had elevated SGOT and SGPT levels of more than three times of upper limit of normal (ULN), respectively.

The prothrombin time was higher than the control for $33 \%$ of patients but the international normalized ratio (INR) was raised more than 1.5 for only $15 \%$ of patients. The mean prothrombin time was 14.13 seconds (SD 1.65) and the mean INR was 0.98 (SD 0.13).

\section{Renal Function}

Serum urea levels were raised in $63 \%$ of patients with mean serum urea of $68 \mathrm{mg} / \mathrm{dL}$ (SD 55), and serum creatinine levels were more than $1.5 \mathrm{mg} / \mathrm{dL}$ in $31 \%$ of patients and more than $2.5 \mathrm{mg} / \mathrm{dL}$ in $6 \%$ of patients with an overall mean of $1.5 \mathrm{mg} / \mathrm{dL}$ (SD 1.71). 


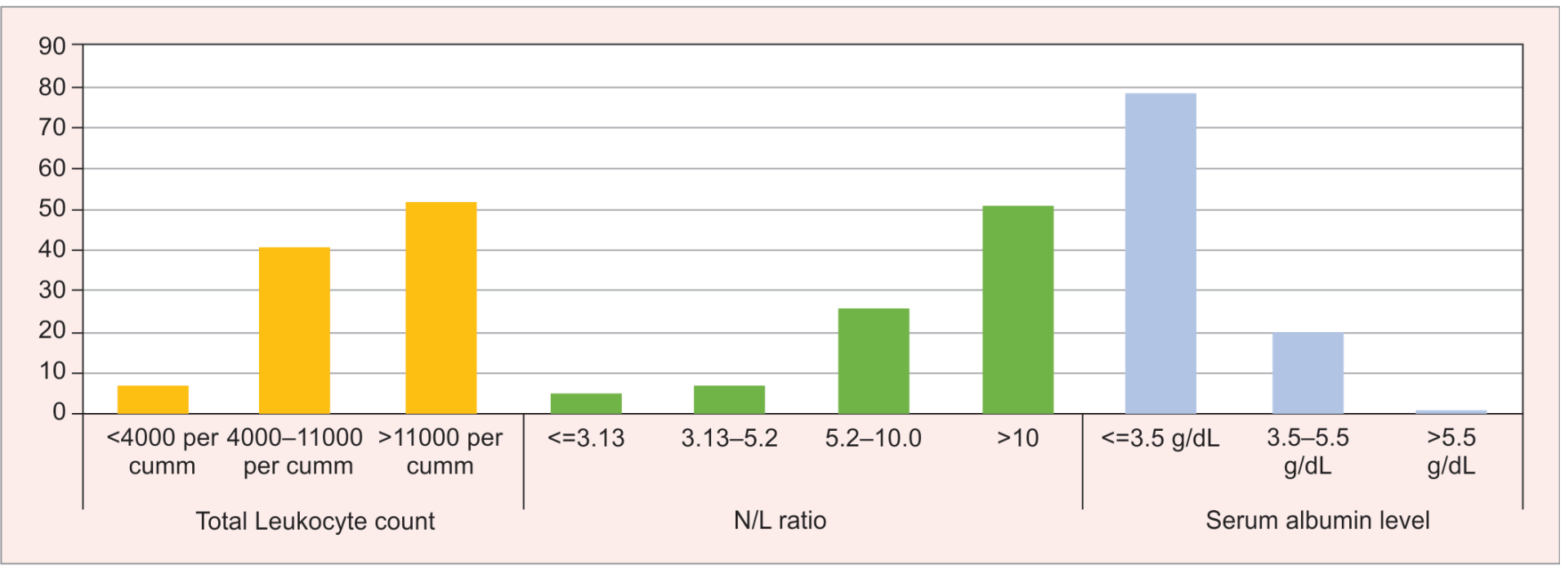

Fig. 3: Distribution of routine investigations $(n=100)$

\section{Serum Electrolytes and Glycemic Status}

The mean sodium level was $137.77 \mathrm{mEq} / \mathrm{L}$ (SD 12.88), hyponatremia was present in $38 \%$ of patients, and hypernatremia in $28 \%$ of patients. The mean potassium level was $4.39 \mathrm{mEq} / \mathrm{L}$ (SD 0.84), hypokalemia was present in $16 \%$, and hyperkalemia in $7 \%$ of patients.

The mean fasting blood glucose was $146 \mathrm{mg} / \mathrm{dL}$ (SD 50) and the mean postprandial blood glucose was $246 \mathrm{mg} / \mathrm{dL}$ (SD 79). Fasting blood glucose was more than $126 \mathrm{mg} / \mathrm{dL}$ for $60 \%$ of patients, and postprandial glucose was more than $200 \mathrm{mg} / \mathrm{dL}$ for $69 \%$ of patients.

\section{Serum Inflammatory Biomarkers}

Six serum biomarkers were studied: C-reactive protein (CRP) had a mean value of $81.14 \mathrm{mg} / \mathrm{L}$ (SD 61.59), ferritin $1276 \mu \mathrm{g} / \mathrm{L}$ (SD 649), D-dimer $5.41 \mu \mathrm{g} / \mathrm{L}$ (SD 11.79), procalcitonin $2.38 \mathrm{ng} / \mathrm{mL}$ (SD 5.84), lactate dehydrogenase (LDH) $1182.49 \mathrm{U} / \mathrm{L}$ (SD 614.36), and interleukin (IL)-6 levels 283.25 (SD 868.86) (Table 3).

Fifty-one percent of patients had a CRP of more than $75 \mathrm{mg} / \mathrm{dL}$ and $84 \%$ had a CRP of more than $25 \mathrm{mg} / \mathrm{dL}$. Fifty-two percent of patients had ferritin levels of more than $1000 \mu \mathrm{g} / \mathrm{L}$ and $10 \%$ had a level of more than $2000 \mu \mathrm{g} / \mathrm{L}$. While raised D-dimer levels of more than $0.5 \mu \mathrm{g} / \mathrm{L}$ were found in $83 \%$ cases, $58 \%$ had levels of more than $1 \mu \mathrm{g} / \mathrm{L}$ and $37 \%$ had levels of more than $2 \mu \mathrm{g} / \mathrm{L}$. Serum LDH levels were over $1000 \mathrm{U} / \mathrm{L}$ for $53 \%$ of patients and more than the normal value of $280 \mathrm{U} / \mathrm{L}$ for all our patients (Fig. 4).

Serum procalcitonin levels were more than $2 \mathrm{ng} / \mathrm{mL}$ in $22 \%$ of patients and more than $0.15 \mathrm{ng} / \mathrm{mL}$ in $75 \%$ of patients and the levels were normal in $13 \%$ of patients. Serum IL- 6 levels were normal for $10 \%$ of patients and more than $100 \mathrm{pg} / \mathrm{mL}$ for $30 \%$ of patients and more than $35 \mathrm{pg} / \mathrm{mL}$ for $47 \%$ of patients.

\section{Electrocardiogram Profile}

Eighty-six percent of patients with COVID-19-related deaths had a normal electrocardiogram (ECG) with $8 \%$ having left-axis deviation and right bundle branch block, ST depression, atrial fibrillation, and tall T wave present in $2 \%$ of patients each (Table 3 ).

\section{Radiological Profile}

Eighty-one percent of the patients had bilateral infiltrates in the chest X-ray, and $9 \%$ had unilateral infiltrates and they were mostly (85\%) peripheral in distribution (Table 3).

Table 3: Serum inflammatory markers and radiological profile $(n=100)$

C-reactive protein [mean (SD) $\mathrm{mg} / \mathrm{dL}$ ]

Ferritin [mean (SD) $\mu \mathrm{g} / \mathrm{L}]$

D-dimer [mean (SD) $\mu \mathrm{g} / \mathrm{L}]$

Procalcitonin [mean (SD) ng/L]

Lactate dehydrogenase[mean (SD) U/L]

Interleukin-6[mean (SD) pg/L]

ECG findings

- Normal

- Left-axis deviation

- Right bundle branch block

- ST depression

- Atrial fibrillation

- Tall T wave

- Wide QRS

Chest X-ray

- Bilateral peripheral infiltrates

- Unilateral infiltrates

- Pleural effusion

- Lung abscess

- Normal

HRCT thorax

- Ground-glass opacity (GGO)

- Consolidation

- Any degree of fibrosis

- Interstitial thickening

- Mediastinal lymphadenopathy

CT severity score [mean (SD)] (out of 25)

Duration of hospital stay [mean (SD) days]

In the high-resolution computed tomography (HRCT) thorax the predominant patterns were ground-glass opacity (GGO) (91\%), consolidation (91\%), fibrosis (even minimal fibrosis was counted) (52\%), and interstitial thickening (53\%) (Table 3).

The mean CT severity score (out of 25) was 17.42 (SD 4.18), 20\% had a score of more than 20 , and $67 \%$ had a score of more than 15 in the HRCT thorax. 


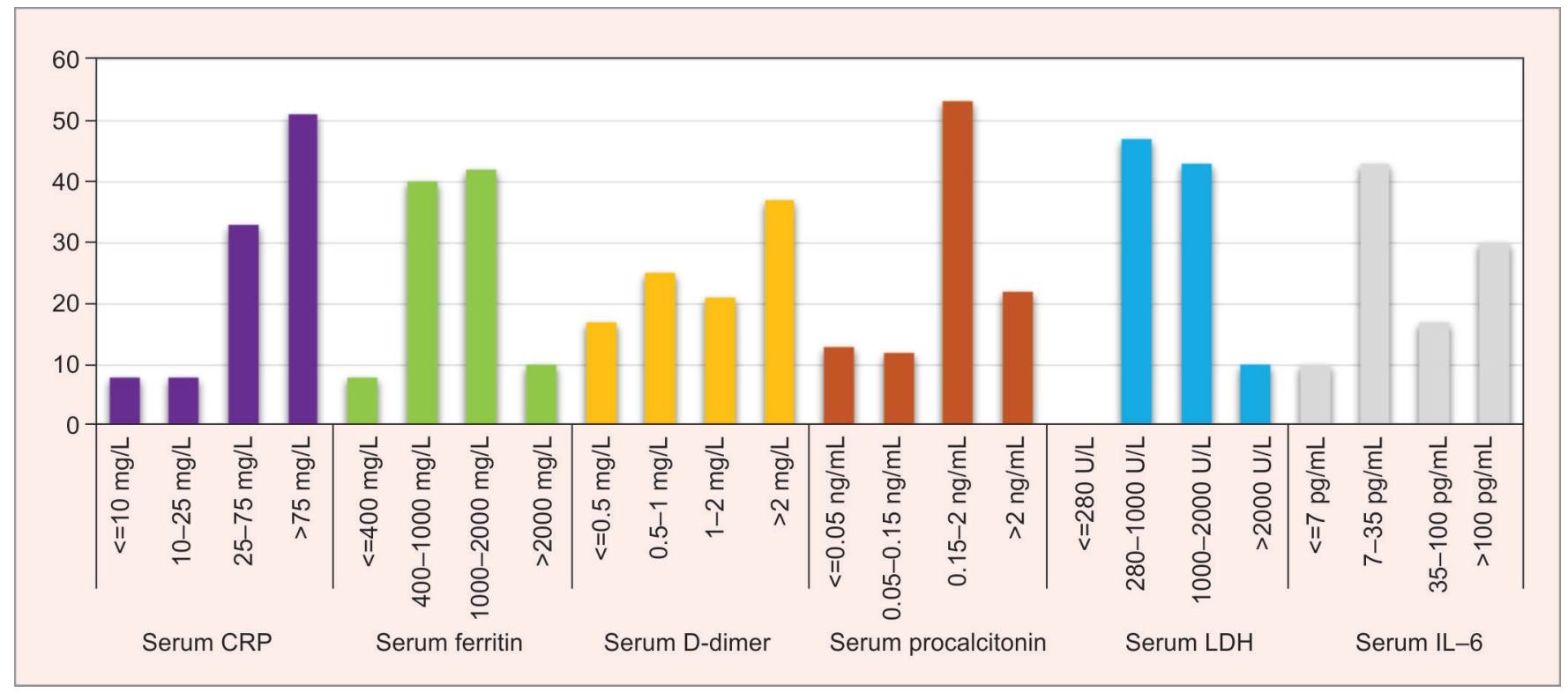

Fig. 4: Distribution of serum inflammatory markers $(n=100)$

\section{Duration of Hospital Stay}

The mean duration of hospital stay was 10.5 days (SD 10.35), 25\% of patients had a duration of stay more than 15 days and $42 \%$ had a duration of stay less than or equal to 5 days.

\section{Discussion}

A lot of lives have already been lost to COVID-19, and the pandemic is still not over. In our single-center retrospective observational study, the main goal was to find out some of the possible in-hospital mortality predictors for the disease.

The data were collected on all in-hospital deaths that occurred in COVID-19-positive patients from September 2020 to April 2021 in the College of Medicine and Sagore Dutta Hospital, which was a COVID-19-dedicated hospital for most of the above-mentioned period.

There are already a few studies that have been done on the topic and below is a comparison with our findings.

\section{Age and Gender}

In a study by Jain et al., ${ }^{2}$ age more than 47 years was stated to be an important factor for mortality and more than $73 \%$ of those were males.

In another study by Suresh et al., ${ }^{3}$ from AlIMS, New Delhi, deaths were associated with increased age, although there was no statistical significance and there was a male preponderance of COVID-19 deaths (73\%) in their study also.

According to research in Pune by Kansara et al., ${ }^{4}$ the mean age of deceased patients was 62 years and $65 \%$ of them were males associated with 1.6 times higher risk of mortality than females.

A study by Mahendra et al. ${ }^{5}$ also stated age more than 50 years to be an independent predictor of mortality in COVID-19 patients with severe pneumonia.

A study by Dhikale et al. ${ }^{6}$ also echoed similar results with respect to the increased age and male preponderance contributing to mortality in COVID-19 patients.

In our study, $61 \%$ were males and the mean age was 68.3 years (SD 13.9); also, $69 \%$ of the study population were over 65 years of age.

\section{Comorbidities}

In the study by Jain et al., ${ }^{2}$ diabetes and hypertension were important mortality predictors with an odds ratio of 2.7 and 2.1, respectively.

Similar findings were reported by various studies conducted by Suresh et al., ${ }^{3}$ Kansara et al., ${ }^{4}$ and Dhikale et al. ${ }^{6}$

In our study, $74 \%$ of the patients had one or two comorbidities and $19 \%$ of them had no reported comorbidity. Only $7 \%$ of patients had more than two comorbidities. Diabetes mellitus and systemic hypertension were found in 57 and $58 \%$ of patients, respectively. CVA (5\%), hypothyroidism (4\%), and CKD (3\%) were other notable comorbidities.

\section{Clinical Profile}

Low oxygen saturation, tachycardia, tachypnea, low Glasgow coma scale, impaired consciousness levels, and high NEWS were reported as important predictors of mortality in various studies done by Jain et al., ${ }^{2}$ Suresh et al., ${ }^{3}$ Kansara et al., ${ }^{4}$ Dhikale et al., ${ }^{6}$ and Myrstad et al. ${ }^{7}$

In our study, oxygen saturation less than $90 \%$ even with supplemental oxygen support, respiratory rate of over 24/minute, tachycardia (Heart rate $>90 /$ minute), NEWS of more than 12 , bilateral crepitations in chest auscultation, and reduced levels of consciousness were all present in high proportions in patients who died due to COVID-19.

\section{Routine Investigations}

A study by Simadibrata et al. ${ }^{8}$ has shown that increased N/L ratios may be strong predictors of mortality in COVID-19 disease.

Studies by Zhu et al. ${ }^{9}$ and Wool et al. ${ }^{10}$ show that high white blood cell (WBC) counts and low platelet counts are associated with higher mortality rates in COVID-19 patients.

In our study, the total leukocyte count was more than $11,000 / \mathrm{mm}^{3}$ in $52 \%$ of patients and less than $4,000 / \mathrm{mm}^{3}$ in $7 \%$ of patients. Most of them had lymphopenia (81\%). The N/L ratio was more than 3.13 in a staggering $94 \%$ of patients, with values 
over 5.2 in $87 \%$ of patients and over 10.0 in $58 \%$ of patients. The platelet count was less than $1,50,000 / \mathrm{mm}^{3}$ in $47 \%$ of patients and was normal in $52 \%$ of patients.

\section{Liver Function Tests}

In a study by Xuet al., ${ }^{11}$ abnormal liver function tests have been stated to be significant contributors of COVID-19-related mortality.

In another study by Ding et al., ${ }^{12}$ abnormal aspartate aminotransferase (AST) and direct bilirubin levels have been stated to be important predictors of mortality in COVID-19-positive patients.

In our study, $79 \%$ of patients had hypoalbuminemia and $8 \%$ of patients had a raised total bilirubin level, out of which most were due to increased direct bilirubin. Around $51 \%$ of patients had an increased SGPT and 73\% of patients had increased SGOT, but only $3 \%$ and $6 \%$ of patients had elevated SGOT and SGPT levels of more than three times of ULN, respectively.

\section{Renal Function}

A study by Trabulus et al. ${ }^{13}$ shows that a reduced estimated glomerular filtration rate (eGFR) is strongly related to deaths in COVID-19 patients. In the study, the eGFR was calculated from age and serum creatinine levels using the CKD-EPI formula.

In our study, serum creatinine levels were more than $1.5 \mathrm{mg} / \mathrm{dL}$ in $31 \%$ of patients and more than $2.5 \mathrm{mg} / \mathrm{dL}$ in $6 \%$ of patients with an overall mean of $1.5 \mathrm{mg} / \mathrm{dL}$ (SD 1.71).

\section{Serum Electrolytes and Glycemic Status}

In a study by Pourfridoni et al., ${ }^{14}$ fluid and electrolyte abnormalities have been shown to be possible risk factors for COVID-19 mortality.

In our study, hyponatremia was present in $38 \%$ of patients, hypernatremia in $28 \%$ of patients, hypokalemia in $16 \%$, and hyperkalemia in $7 \%$ of patients.

\section{Serum Inflammatory Biomarkers}

There are many studies that support the role of inflammatory markers in predicting COVID-19-related deaths. Some of them are studies by Jain et al., ${ }^{2}$ Archana et al., ${ }^{15}$ Nadeem et al., ${ }^{16}$ and Ahmeidi et al. ${ }^{17}$

Six serum biomarkers were studied:51\% of patients had a CRP of more than $75 \mathrm{mg} / \mathrm{dL}, 52 \%$ of patients had ferritin levels of more than $1000 \mu \mathrm{g} / \mathrm{L}, 58 \%$ had $D$-dimer levels of more than $1 \mu \mathrm{g} / \mathrm{L}$,serum LDH levels were over $1000 \mathrm{U} / \mathrm{L}$ for $53 \%$ of patients, serum procalcitonin levels were more than $0.15 \mathrm{ng} / \mathrm{mL}$ in $75 \%$ of patients, and serum IL-6 levels were more than $100 \mathrm{pg} / \mathrm{mL}$ for $30 \%$ of patients.

\section{Radiological Profile}

After browsing through the relevant literature, it was found that there was very limited evidence regarding the role of radiological profiles in predicting the mortality in COVID-19-positive patients.

In our study, $81 \%$ of the patients had bilateral infiltrates in the chest X-ray, which were mostly (85\%) peripheral in distribution.

In the HRCT thorax, the predominant patterns were GGO (91\%), consolidation (91\%), fibrosis (even minimal fibrosis was counted) (52\%), and interstitial thickening (53\%), and the CT severity score (out of 25) was more than 15 in $67 \%$ of the patients.

\section{Summary and Conclusions}

In our study, there seems to be a male preponderance among the patients with COVID-19-related deaths, which might mean that gender may be a risk factor for COVID-19-related deaths, the risk being more among the male population.

Age also seems to be a strong possible risk factor with more deaths seen in over 65 years of age.

The association of diabetes mellitus and systemic hypertension as comorbidity also appears to be an important mortality risk factor in COVID-19 patients.

The oxygen saturation less than $90 \%$ with optimal supplemental oxygen support, respiratory rate of more than 24 /minute, heart rate of more than 90 /minute, NEWS of more than 12 , bilateral crepitations on chest auscultation, and any degree of loss in the level of consciousness all are potential mortality risk factors for COVID-19 patients.

Increase total leukocyte count above $11,000 / \mathrm{mm}^{3}, \mathrm{~N} / \mathrm{L}$ ratios above 5.2, low platelets levels below $1.5 \mathrm{lakhs} / \mathrm{mm}^{3}$, serum albumin levels below $3.5 \mathrm{~g} / \mathrm{dL}$, hypo- or hypernatremia (serum sodium $<135$ or $>145 \mathrm{mEq} / \mathrm{L}$ ), and impaired glycemic status were all found to be potential mortality predictors for COVID-19-related deaths.

Among the serum inflammatory biomarkers, CRP levels more than $75 \mathrm{mg} / \mathrm{dL}$, ferritin levels more than $1000 \mu \mathrm{g} / \mathrm{L}$, D-dimer levels more than $1 \mu \mathrm{g} / \mathrm{L}$, procalcitonin levels more than $0.15 \mathrm{ng} / \mathrm{mL}, \mathrm{LDH}$ levels more than $1000 \mathrm{U} / \mathrm{L}$, and IL-6 levels more than $100 \mathrm{pg} / \mathrm{mL}$ could be strong predictors of mortality for COVID-19-related deaths according to our study.

Bilateral and peripheral infiltrates in chest X-ray, GGO, consolidation, and any degree of fibrosis in the HRCT thorax are the most common patterns known in COVID-19, and when associated with a CT severity score of more than 15 out of 25 , could well be predictors of mortality for the disease too.

Many patients died in the first 5 days, most of whom had multiple comorbidities or long-standing disease or hospitalization history beforehand. However, for others, a hospital stay for more than 15 days significantly appears to affect mortality.

\section{Limitations of Study}

The greatest limitation is perhaps the sample size and time allotted to this study.

Moreover, this is a descriptive study and no statistical inferences can be made from this. No comparisons have been made with survivors of COVID-19 or with people free from COVID-19 from the same population.

Many of the parameters and radiological profiles studied are dynamic in nature and can change dramatically as the disease progresses, as already seen from our clinical experience of the disease's natural history. So, it is very difficult to get an accurate representation from all such values and profiles.

Even though the study is on COVID-19-related deaths, a small part of the sample may also have other contributory causes of death, which may affect the estimation of the actual impact of COVID-19 itself toward death.

Finally, since this is a single-center study, there is always the chance of hospital bias or Berkson's bias.

These are the reasons for which a large number of studies are required to this end to improve the accuracy of our predictions, and this study will only help in guiding the formulation of multiple hypotheses, which may be used for later analytical studies. 


\section{References}

1. WHO. WHO coronavirus (COVID-19) dashboard. 2021. Available from: https://covid19.who.int/.

2. Jain AC, Kansal S, Raman S, et al. A retrospective observational study to determine the early predictors of in-hospital mortality at admission with COVID-19. Indian J Crit Care Med 2020;24(12):1174-1179. DOI: 10.5005/jp-journals-10071-23683.

3. Suresh S, Tiwari A, Mathew R, et al. Predictors of mortality and the need of mechanical ventilation in confirmed COVID-19 patients presenting to the emergency department in North India. J Family MedPrim Care 2021;10:542-549. DOI: 10.4103/jfmpc. jfmpc_1775_20.

4. Kansara N, Nandapurkar AB, Maniyar R, et al. Prediction of mortality by age and multi-morbidities among confirmed COVID-19 patients: secondary analysis of surveillance data in Pune, Maharashtra, India. Indian J Public Health 2021;65:64-66. DOI: 10.4103/ijph. IJPH_1096_20.

5. Mahendra M, Nuchin A, Kumar R, et al. Predictors of mortality in patients with severe COVID-19 pneumonia - a retrospective study. Adv Respir Med 2021;89(2):135-144. DOI: 10.5603/ARM.a2021.0036.

6. Dhikale PT, Chavhan SS, Adsul BB, et al. Predictors for mortality of inpatients of COVID-19 in Mumbai. Int J Commun Med Public Health 2021;8(6):3079-3083. DOI: 10.18203/2394-6040.ijcmph20212019.

7. Myrstad M, Ihle-Hansen $H$, Tveita AA, et al. National Early Warning Score 2 (NEWS2) onadmission predicts severe disease and in-hospital mortality from Covid-19 - aprospective cohort study. Scand J Trauma Resusc Emerg Med 2020;28:66. DOI: 10.1186/s13049-02000764-3.

8. Simadibrata DM, Calvin J, Wijaya AD, et al. Neutrophil-to-lymphocyte ratio on admission to predict the severity and mortality of COVID-19 patients: a meta-analysis. Am J Emerg Med 2021;42:60-69. DOI: 10.1016/j.ajem.2021.01.006.

9. Zhu B, Feng X, Jiang C, et al. Correlation between white blood cell count at admission and mortality in COVID-19 patients: a retrospective study. BMC Infect Dis 2021;21(1):574. DOI: 10.1186/ s12879-021-06277-3.

10. Wool GD, Miller JL. The impact of COVID-19 disease on platelets and coagulation. Pathobiology 2020;88:15-27. DOI: 10.1159/000512007.

11. Xu W, Huan C, Fei L, et al. Dynamic changes in liver function tests and their correlation with illness severity and mortality in patients with COVID-19: a retrospective cohort study. ClinIntervAging2021;16:675-685. DOI: 10.2147/CIA.S303629.

12. Ding Zy, Li Gx, Chen L, et al. Association of liver abnormalities with in-hospital mortality inpatients with COVID-19. J Hepatol 2020;74:1295-1302. DOI: 10.1016/j.jhep.2020.12.012.

13. Trabulus S, Karaca C, Balkan II, et al. Kidney function on admission predicts in-hospital mortality in COVID-19. PLoS One 2020;15(9):e0238680. DOI: 10.1371/journal.pone.0238680.

14. Pourfridoni M, Abbasnia SM, Shafaei F, et al. Fluid and electrolyte disturbances in COVID-19 and their complications. BioMed ResInt 2021;9. DOI: 10.1155/2021/6667047.

15. Archana B, Shyamsunder S, Das R. Validity of markers and indexes of systemic inflammation in predicting mortality in COVID 19 infection: a hospital based cross sectional study. BMJ Yale 2021. DOI: 10.1101/2021.03.30.21254635.

16. Nadeem R, Elhoufi AM, lqbal NE, et al. Prediction of cytokine storm and mortality in patients with COVID-19 admitted to ICU: do markers tell the story? Dubai Med J 2021. DOI: 10.1159/000514406.

17. Ahmeidi AA, Musa A, Ahmed HS, et al. Inflammatory markers as predictors of mortality in COVID-19 infection. Afr J Lab Med 2020;9(1):1298. DOI: 10.4102/ajlm.v9i1.1298. 